\title{
Impact of local administration of various doses of dexmedetomidine on ropivacaine-induced lumbar plexus-sciatic nerve block
}

\author{
JIAN YU, SHIQIANG SHAN and YU NIE \\ Department of Anesthesiology, Central Hospital of Cangzhou, Cangzhou, Hebei 061000, P.R. China
}

Received April 23, 2017; Accepted December 15, 2017

DOI: $10.3892 /$ etm.2018.6218

\begin{abstract}
The present study aimed to investigate the impact of various doses of dexmedetomidine (DEX) on ropivacaine (ROP)-induced lumbar plexus-sciatic nerve block (LSB). A total of 80 patients who underwent ankle surgery under LSB were divided into group $\mathrm{R}$ (applied with $30 \mathrm{ml} \mathrm{5 \%} \mathrm{ROP),}$ Dex1 (30 ml 0.5\% ROP + $1 \mu \mathrm{g} / \mathrm{kg}$ DEX), Dex2 (30 ml 0.5\% $\mathrm{ROP}+1.5 \mu \mathrm{g} / \mathrm{kg} \mathrm{DEX})$ and Dex3 $(30 \mathrm{ml} 0.5 \% \mathrm{ROP}+2 \mu \mathrm{g} / \mathrm{kg}$ DEX), with 20 cases in each group. The onset time and duration of sensory and motor block, mean arterial pressure (MAP), heart rate (HR), oxygen saturation, Ramsay score, serum vascular endothelial growth factor (VEGF) level and adverse reactions in the four groups were observed. Results demonstrated that the durations of sensory and motor block in group $\mathrm{R}$ were shorter than those in groups Dex1-3 $(\mathrm{P}<0.01)$, followed by the sequence of group Dex $1<\operatorname{Dex} 2<\operatorname{Dex} 3(\mathrm{P}<0.05)$. MAP and HR in groups Dex1-3 at T2-T5 were significantly lower than those in group $\mathrm{R}(\mathrm{P}<0.01)$, and $\mathrm{HR}$ in group Dex3 at $\mathrm{T} 3$ and T4 was significantly lower than that in groups Dex1 and Dex2 $(\mathrm{P}<0.05)$. Ramsay scores in groups Dex 1-3 at T2-T4 were significantly higher than those in group $\mathrm{R}(\mathrm{P}<0.05)$. Serum VEGF levels in groups Dex2 and Dex3 at T2-T5 were significantly higher than those in group $\mathrm{R}(\mathrm{P}<0.01)$. The incidences of over-sedation, bradycardia and dry mouth in group Dex3 were notably higher than those in the other groups. In conclusion, $1.5 \mu \mathrm{g} / \mathrm{kg}$ DEX exhibits a superior effect in improving ROP-induced LSB.
\end{abstract}

\section{Introduction}

Ankle surgery is a common orthopedic surgery with various methods for anesthesia. Currently, controversy exists regarding the anesthetic methods in clinical practice of lower limb surgery. Traditional anesthesia is based on lumbar plexus-epidural

Correspondence to: Dr Jian Yu, Department of Anesthesiology, Central Hospital of Cangzhou, 16 Xinhua West Road, Cangzhou, Hebei 061000, P.R. China

E-mail: jianyucz@yeah.net

Key words: dexmedetomidine, ropivacaine, nerve block, dose anesthesia. Although this method may meet the surgical requirement, it has multiple postoperative complications, and may lead to greater hemodynamic changes, including rapid blood pressure decrease or even respiratory and circulatory inhibition $(1,2)$. Therefore, ensuring intraoperative anesthetic safety and reducing surgical and anesthetic complications are essential $(3,4)$. In recent years, the application of peripheral nerve block technology has attracted much attention (5-7). Lumbar plexus-sciatic nerve block (LSB) has less interference on patients' respiration and circulation in lower extremity surgery, and does not affect the gastrointestinal and urinary functions (5-7). In addition, it may avoid lumbar puncture injury and achieve accurate positioning in peripheral nerve block anesthesia when using a nerve stimulator, as well as long anesthetic duration and satisfactory results (3-5). Ropivacaine (ROP) is a long-acting amide local anesthetic that is widely used within clinics due to its low toxicity towards the central nervous system and cardiovascular system (8). Furthermore, it is able to achieve sensory and motor anesthesia, separately (9).

It has been demonstrated that clonidine, an $\alpha 2$-adrenergic receptor $(2 \mathrm{AR})$ agonist, may enhance analgesic and anesthetic effects when used for peripheral nerve block (10). Dexmedetomidine (DEX) is a novel highly selective $\alpha 2 \mathrm{AR}$ agonist. Its binding ratio of $\alpha 2$ : $\alpha 1$ receptor is $1,620: 1$, which is eight times that of clonidine (11). Its distribution and elimination half-lives when intravenously injected are $6 \mathrm{~min}$ and $2 \mathrm{~h}$, respectively (11). Meanwhile, it also serves roles including analgesia, sedation, stress inhibition and stabilization of hemodynamics (11). It has been reported that the local application of DEX combined with anesthetics may prolong the effects of nerve block, reduce the local anesthetic dosage, prolong the effect time and enhance the analgesic effects; furthermore, it has no neurotoxicity (12-16). However, the impact of DEX dose on ROP-induced LSB is not clear. The present study evaluated the impact of different doses of DEX on ROP-induced LSB. The objective of the present study was to provide a reference for further application of DEX to clinical local anesthesia.

\section{Patients and methods}

Patients. A total of 80 patients undergoing selective or acute LSB-based ankle surgery (American Society of Anesthesiologists (ASA) grading I-II) (17) at the Central Hospital of Cangzhou (Cangzhou, China) from January 2013 
to August 2013 were enrolled in the present study. There were 47 males and 33 females, with an age range of 18-63 years and body weight range of $47-83 \mathrm{~kg}$. The preoperative heart, lung, liver and kidney functions were normal. The exclusion criteria were as follows: Neuromuscular diseases, coagulation disorders, diabetes, sinus bradycardia or atrioventricular block, mental disorders or taking analgesics recently and infection at the nerve block site. The patients were double-blindly and randomly divided into group $\mathrm{R}$ [applied $30 \mathrm{ml}$ 5\% ROP (batch no. NACL; AstraZeneca, Cambridge, UK)], group Dex1 [a total of $30 \mathrm{ml}$ of $0.5 \% \mathrm{ROP}+1 \mu \mathrm{g} / \mathrm{kg}$ DEX (batch no. 1512066211 ; Cisen Pharmaceutical Co., Ltd., Jining, China)], group Dex2 (a total of $30 \mathrm{ml} 0.5 \% \mathrm{ROP}+1.5 \mu \mathrm{g} / \mathrm{kg} \mathrm{DEX}$ ) and group Dex3 (a total of $30 \mathrm{ml}$ of $0.5 \% \mathrm{ROP}+2 \mu \mathrm{g} / \mathrm{kg} \mathrm{DEX}$ ), with 20 cases in each group. The applied drugs were not prepared by the physicians involved in the present study. The present study was approved by the Medical Ethics Committee of the Central Hospital of Cangzhou. Written informed consent was obtained from all patients.

Anesthetic methods. All patients had not received preoperative medication. During the surgery, one intravenous channel was firstly established for the infusion of Ringer's solution (6-8 ml/kg). Additionally, electrocardiogram, heart rate (HR), oxygen saturation $\left(\mathrm{SpO}_{2}\right)$ and mean arterial pressure (MAP) were routinely monitored. The positive electrode of one nerve stimulator was connected to the skin electrode of the patient's leg, and the negative electrode was connected to the nerve stimulation needle $(0.8 \times 100 \mathrm{~mm})$. The stimulation current intensity started from $1 \mathrm{~mA}$ together with a stimulation frequency of $2 \mathrm{~Hz}$, and the pulse was set as $0.1 \mathrm{msec}$. Lumbar plexus block utilized the method of intra-psoas major muscle block as follows: The patient was placed on the lateral side with knees and hip flexed and the block side upwards. The vertical line between the middle line (formed by lining along the spinous processes of the lumbar spine) and the posterior superior iliac crest was divided into three equal parts, and the needling point was at the mediolateral one-third site and 1-cm deflecting toward the head, so that it could induce the shrink of the quadriceps femoris. Sciatic nerve block used the posterior approach as follows: The patient was placed in the improved Sims supine position (the non-surgical side was fully extended, the surgical side was flexed at the hip and the knees were upward). The line connecting the posterior iliac crest and the posterior edge of the greater trochanter was drawn at mid-normal, and the needling point was located at the intersection where the above line extended $3-5 \mathrm{~cm}$ and intersected with the line of the greater trochanter and sacral hiatus, so it could induce strephenopodia of ankle metatarsal flexure or strephexopodia of ankle dorsal flexure. If the corresponding induced response was obvious, the intensity was gradually reduced to $0.3-0.4 \mathrm{~mA}$. If there was sustained induced motor response, and the suction of the syringe connecting to the end of the needle indicated no blood or cerebrospinal fluid, $20 \mathrm{ml}$ anesthetic (as aforementioned) for lumbar plexus block was injected together with sciatic nerve block using $10 \mathrm{ml}$ of anesthetic.

Observation indexes. Visual Analogue Scale (VAS) pain scores obtained by needling the femoral innervation area (the patella in front of the thigh) and the sciatic innervation area (the lateral side of the dorsum pedis) every 3 min after block were used to evaluate the block effects ( 0 points, painless; 10 points, unendurable pain). Meanwhile, the onset time of block (from the end of the injection to VAS score $<4$ points) and the duration of sensory block (from the end of the injection to VAS score $\geq 4$ points) were also recorded. The movements of the knee and ankle joints were evaluated, and the effects of motor block were evaluated using the modified Bromage Muscle Relaxation score (0 points, no motor nerve block, the knee and tibia joints could freely move; 1 point, the lower limb could not be raised high and straight, but the knee and ankle joints could be active; 2 points, the lower limb could not be raised high and straight, the knee joints could not be bent, but the ankle joints could be active; 3 points, the lower limbs were completely blocked, could not be raised high and straight, and the knee and ankle joints could not flex). The onset time of block (from the end of the injection to Bromage score=1 point) and duration of motor nerve block (from the block onset to the recovery of ankle motor function) were recorded.

Sedation was evaluated using the Ramsay score (1 point, irritable; 2 points, quiet, cooperative and with good orientation; 3 points, drowsy, but still responsive to commands; 4 points, light sleep, but still active when tapping the forehead; 5 points, sleep, and dull to the forehead tapping stimulation; 6 points, deep sleep, having no response to the forehead tapping stimulation). The values of MAP, $\mathrm{HR}, \mathrm{SpO}_{2}$, Ramsay score and serum vascular endothelial growth factor (VEGF) level (18) were recorded at the time of entry into the surgery room (T0), immediately after anesthesia (T1), $10 \mathrm{~min}$ after anesthesia (T2), 30 min after anesthesia (T3), $1 \mathrm{~h}$ after anesthesia (T4) and end of surgery (T5).

A total of $10 \mathrm{mg}$ intravenous ephedrine $(30 \mathrm{mg} / \mathrm{ml}$; Northeast Pharmaceutical Group Co.,Ltd., Shenyang, China) or $0.5 \mathrm{mg}$ atropine $(0.5 \mathrm{mg} / \mathrm{ml}$; Jiangsu Lianshui Pharmaceutical Co., Ltd., Lianshui, China) was applied if intraoperative hypotension (basal value reduction $>30 \%$ or systolic pressure $<90 \mathrm{mmHg}$ ) or bradycardia ( $\mathrm{HR}<50$ beats/min) occurred; mask-assisted breathing was applied in the cases of respiratory depression (respiratory rate $<12$ times/min), poor breathing or $\mathrm{SpO}_{2}<90 \%$. The patients with intraoperative pain complaint were intravenously administered with $0.2 \mu \mathrm{l}$ sufentanil (75 $\mu \mathrm{g} / \mathrm{ml}$; Yichang Renfu Pharmaceutical Co., Ltd., Yichang, China). If the pain remained too strong for the patient to endure the surgery, general anesthesia was applied; however, in this case, the patient should be excluded from the study. The adverse reactions during and following surgery, including over-sedation (Ramsay score $\geq 5$ points), bradycardia, dry mouth, hypotension, respiratory depression, nerve root stimulation, urine retention and local anesthetic toxicity, were recorded.

Statistical analysis. All statistical analysis was performed using SPSS 13.0 (SPSS, Inc., Chicago, IL, USA). The enumeration data were presented as number, and were compared using the $\chi^{2}$ test. The measurement data were presented as the mean \pm standard deviation, and were compared using one-way analysis of variance followed by Student-Newman-Keuls-q test. $\mathrm{P}<0.05$ was considered to indicate a statistically significant difference. 
Table I. General data of patients in the four groups ( $n=20 /$ group).

\begin{tabular}{lcccr}
\hline & \multicolumn{4}{c}{ Group } \\
\cline { 2 - 5 } Characteristic & $\mathrm{R}$ & Dex 1 & Dex2 & Dex3 \\
\hline Age, years & $43.11 \pm 12.36$ & $39.67 \pm 14.38$ & $41.09 \pm 10.56$ & $36.77 \pm 13.45$ \\
Gender, $\mathrm{n}$ (male/female) & $10 / 10$ & $12 / 8$ & $9 / 11$ & $11 / 9$ \\
Body mass index, $\mathrm{kg} / \mathrm{m}^{2}$ & $20.78 \pm 4.34$ & $21.82 \pm 4.56$ & $19.56 \pm 3.45$ & $22.56 \pm 4.90$ \\
ASA grade, $\mathrm{n}(\mathrm{I} / \mathrm{II})$ & $8 / 12$ & $9 / 11$ & $7 / 13$ & $8 / 12$ \\
Surgery time, $\min$ & $72.67 \pm 4.45$ & $71.34 \pm 6.76$ & $73.67 \pm 8.32$ & $72.06 \pm 7.89$ \\
\hline
\end{tabular}

$\mathrm{R}$, group administered $30 \mathrm{ml}$ 5\% ROP; Dex1, group administered $30 \mathrm{ml} \mathrm{0.5 \%} \mathrm{ROP} \mathrm{+} 1 \mu \mathrm{g} / \mathrm{kg}$ DEX; Dex2, group administered $30 \mathrm{ml} 0.5 \%$ $\mathrm{ROP}+1.5 \mu \mathrm{g} / \mathrm{kg}$ DEX; Dex3, group administered $30 \mathrm{ml}$ 0.5\% ROP + $2 \mu \mathrm{g} / \mathrm{kg}$ DEX; ROP, ropivacaine; DEX, dexmedetomidine; ASA, American Society of Anesthesiologists.

Table II. Comparison of onset time and duration of sensory and motor block among the four groups (n=20/group).

\begin{tabular}{|c|c|c|c|c|c|}
\hline \multirow[b]{2}{*}{ Site } & \multirow[b]{2}{*}{ Group } & \multicolumn{2}{|c|}{ Sensory block } & \multicolumn{2}{|c|}{ Motor block } \\
\hline & & Onset time, $\min$ & Duration, min & Onset time, $\min$ & Duration, min \\
\hline \multirow[t]{4}{*}{ Lumbar plexus } & $\mathrm{R}$ & $13.35 \pm 4.67$ & $457.47 \pm 213.19$ & $17.28 \pm 4.79$ & $329.70 \pm 52.60$ \\
\hline & Dex1 & $12.87 \pm 5.42$ & $862.33 \pm 297.49^{a}$ & $16.65 \pm 4.33$ & $649.20 \pm 187.51^{\mathrm{a}}$ \\
\hline & Dex2 & $13.16 \pm 3.65$ & $1,232.74 \pm 209.38^{a, b}$ & $16.57 \pm 5.46$ & $831.32 \pm 232.20^{\mathrm{a}, \mathrm{b}}$ \\
\hline & Dex3 & $12.34 \pm 4.86$ & $1,564.44 \pm 261.54^{\mathrm{a}-\mathrm{c}}$ & $16.63 \pm 6.22$ & $1,200.78 \pm 241.10^{\mathrm{a}-\mathrm{c}}$ \\
\hline \multirow[t]{4}{*}{ Sciatic nerve } & $\mathrm{R}$ & $12.34 \pm 4.59$ & $379.44 \pm 65.54$ & $15.66 \pm 5.46$ & $310.10 \pm 67.43$ \\
\hline & Dex1 & $11.55 \pm 4.22$ & $741.74 \pm 217.21^{\mathrm{a}}$ & $15.71 \pm 5.53$ & $587.18 \pm 249.63^{\mathrm{a}}$ \\
\hline & Dex2 & $11.33 \pm 5.56$ & $979.33 \pm 206.13^{\mathrm{a}, \mathrm{b}}$ & $16.88 \pm 4.64$ & $782.50 \pm 251.73^{a, b}$ \\
\hline & Dex3 & $11.72 \pm 5.31$ & $1,242.5 \pm 187.63^{\mathrm{a}-\mathrm{c}}$ & $16.52 \pm 5.69$ & $1,106.53 \pm 249.77^{\mathrm{a}-\mathrm{c}}$ \\
\hline
\end{tabular}

${ }^{\mathrm{a}} \mathrm{P}<0.01$ vs. group $\mathrm{R}$; ${ }^{\mathrm{b}} \mathrm{P}<0.05$ vs. group Dex $1 ;{ }^{\mathrm{c}} \mathrm{P}<0.05$ vs. group Dex $2 . \mathrm{R}$, administered $30 \mathrm{ml} 5 \% \mathrm{ROP}$; Dex 1 , group administered $30 \mathrm{ml} 0.5 \%$ $\mathrm{ROP}+1 \mu \mathrm{g} / \mathrm{kg}$ DEX; Dex2, group administered $30 \mathrm{ml} \mathrm{0.5 \%} \mathrm{ROP} \mathrm{+} 1.5 \mu \mathrm{g} / \mathrm{kg} \mathrm{DEX}$; Dex3, group administered $30 \mathrm{ml} 0.5 \% \mathrm{ROP}+2 \mu \mathrm{g} / \mathrm{kg}$ DEX; ROP, ropivacaine; DEX, dexmedetomidine.

\section{Results}

General data of patients. The general data of patients are demonstrated in Table I. There was no significant difference in age, gender, body mass index, ASA grade or surgery time among the four groups $(\mathrm{P}>0.05)$.

Overall outcome. All patients successfully completed the surgery. No patient required sufentanil administration or was switched to other anesthetic methods.

Comparison of onset time, and duration of sensory and motor block among the four groups. As demonstrated in Table II, there was no significant difference in the onset time of sensory or motor block at the lumbar plexus or sciatic nerve among the four groups $(\mathrm{P}>0.05)$. Compared with group $\mathrm{R}$, the durations of sensory and motor block at the lumbar plexus or sciatic nerve in groups Dex 1-3 were significantly prolonged $(\mathrm{P}<0.01)$. Furthermore, the durations in groups Dex 3 and Dex 2 were significantly longer than those in group Dex1 $(\mathrm{P}<0.05)$, and the duration in group Dex3 was significantly longer than that in group Dex $2(\mathrm{P}<0.05)$.

Comparison of MAP, HR and $\mathrm{SpO}_{2}$ among the four groups. MAP in groups Dex1-3 at T2-T5 was significantly lower than that of the same group at $\mathrm{T} 0$ and $\mathrm{T} 1$, respectively $(\mathrm{P}<0.01)$. There was no significant difference in MAP between the different time points in group $\mathrm{R}(\mathrm{P}>0.05)$. The intergroup comparison revealed that MAP in groups Dex1-3 at T2-T5 was significantly lower than that in group $\mathrm{R}(\mathrm{P}<0.01)$. There was no significant difference in each index at each time point between groups Dex1-3 ( $\mathrm{P}>0.05)$ (Fig. 1). HR in groups Dex1-3 at T2-T5 was also significantly lower than those in the same group at T0 and $\mathrm{T} 1$, respectively $(\mathrm{P}<0.01)$. There was no significant difference in $\mathrm{HR}$ between the different time points in group $\mathrm{R}(\mathrm{P}>0.05)$. Compared with group $\mathrm{R}, \mathrm{HR}$ in groups Dex1-3 at T2-T5 was significantly reduced, respectively $(\mathrm{P}<0.01)$. In addition, HR in group Dex3 at T3 and T4 was significantly lower than that in groups Dex1 and Dex2, respectively $(\mathrm{P}<0.05)$. There was no significant difference in 


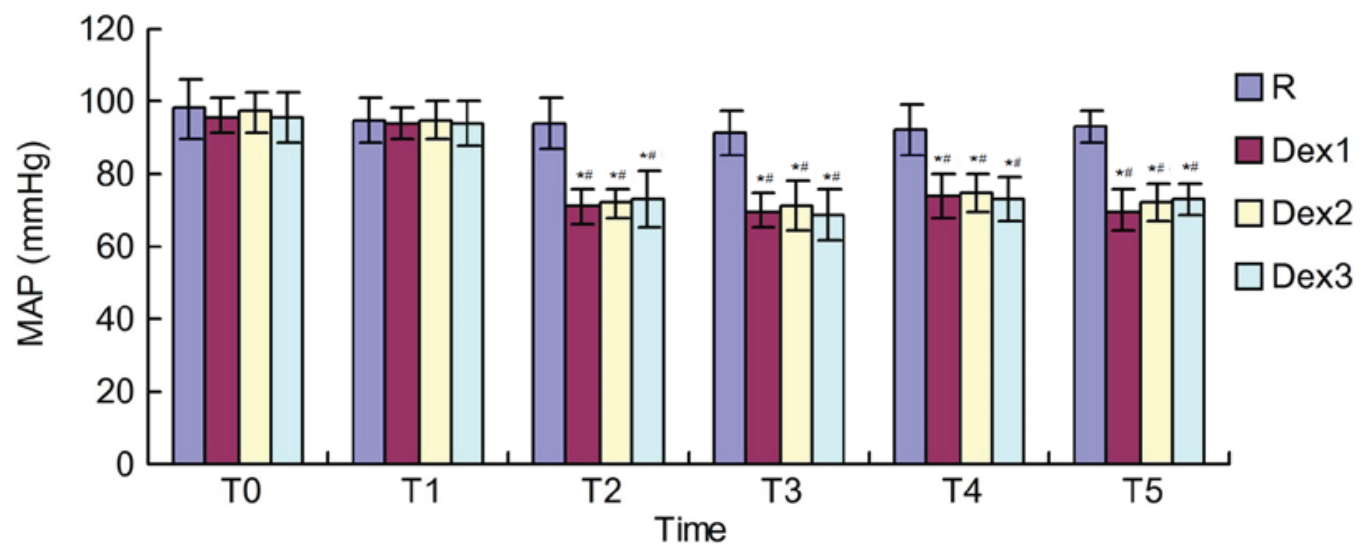

Figure 1. Comparison of MAP among the four groups ( $\mathrm{n}=20 /$ group). ${ }^{*} \mathrm{P}<0.01$ vs. the same group at $\mathrm{T} 0$ and $\mathrm{T} 1 ;{ }^{*} \mathrm{P}<0.01$ vs. group $\mathrm{R}$ at the same time point. MAP, mean arterial pressure; R, group administered $30 \mathrm{ml}$ 5\% ROP; Dex1, group administered $30 \mathrm{ml} 0.5 \% \mathrm{ROP}+1 \mu \mathrm{g} / \mathrm{kg}$ DEX; Dex 2 , group administered $30 \mathrm{ml}$ $0.5 \% \mathrm{ROP}+1.5 \mu \mathrm{g} / \mathrm{kg}$ DEX; Dex3, group administered $30 \mathrm{ml}$ 0.5\% ROP + $2 \mu \mathrm{g} / \mathrm{kg}$ DEX; ROP, ropivacaine; DEX, dexmedetomidine.

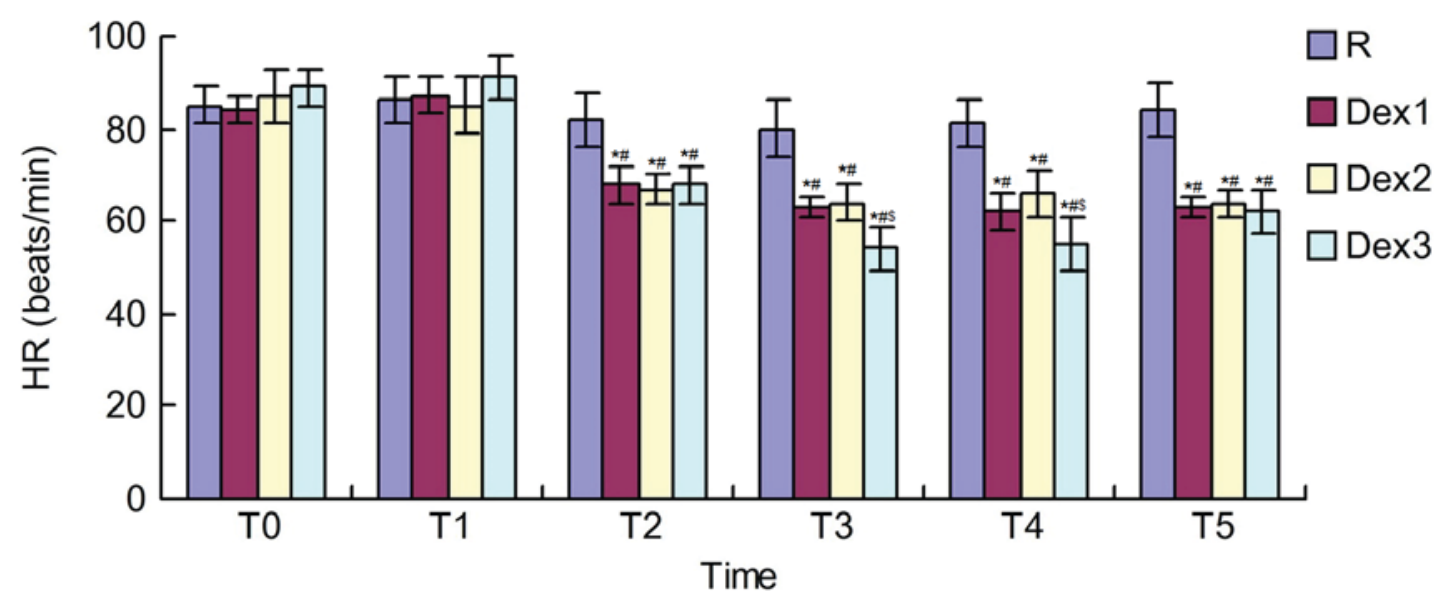

Figure 2. Comparison of HR among the four groups ( $\mathrm{n}=20$ /group). ${ }^{*} \mathrm{P}<0.01$ vs. the same group at $\mathrm{T} 0$ and $\mathrm{T} 1 ;{ }^{\sharp} \mathrm{P}<0.01$ vs. group $\mathrm{R}$ at the same time point; ${ }^{\$} \mathrm{P}<0.05$ vs. Dex 1 and Dex2 at the same time point. HR, heart rate; R, group administered $30 \mathrm{ml} 5 \% \mathrm{ROP}$; Dex 1 , group administered $30 \mathrm{ml} 0.5 \% \mathrm{ROP}+1 \mu \mathrm{g} / \mathrm{kg}$ DEX; Dex2, group administered $30 \mathrm{ml}$ 0.5\% ROP + $1.5 \mu \mathrm{g} / \mathrm{kg}$ DEX; Dex3, group administered $30 \mathrm{ml} 0.5 \%$ ROP + $2 \mu \mathrm{g} / \mathrm{kg}$ DEX; ROP, ropivacaine; DEX, dexmedetomidine.

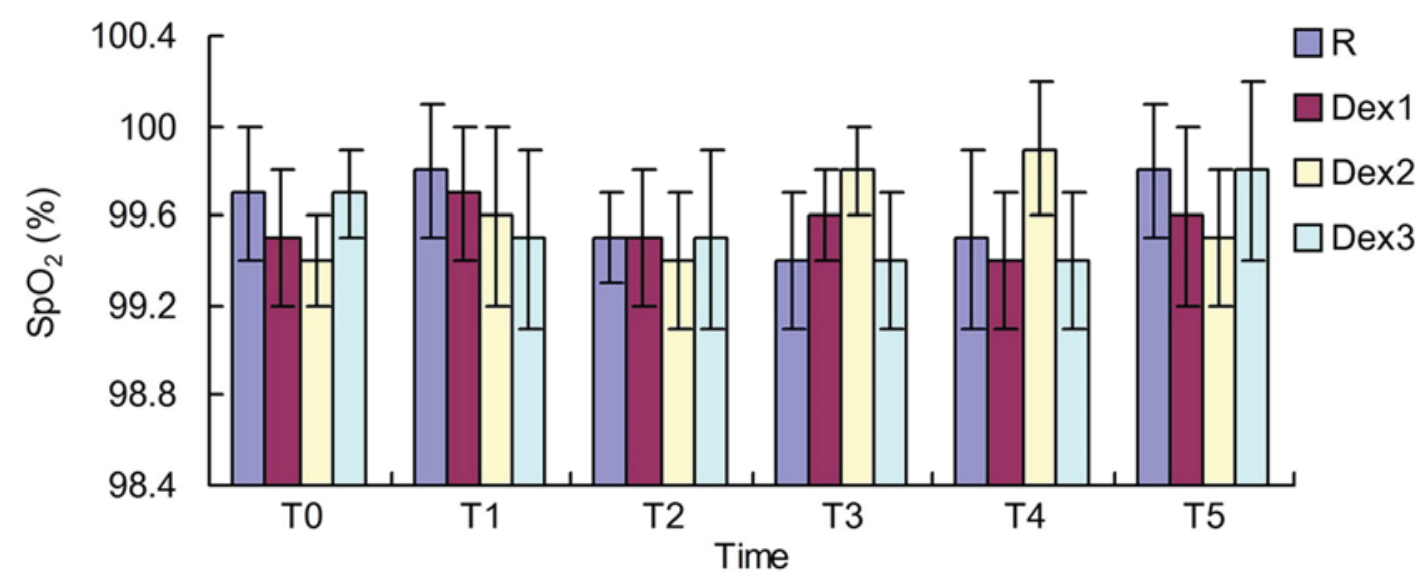

Figure 3. Comparison of $\mathrm{SpO}_{2}$ among the four groups (n=20/group). $\mathrm{SpO}_{2}$, oxygen saturation; R, group administered $30 \mathrm{ml} \%$ ROP; Dex1, group administered $30 \mathrm{ml}$ 0.5\% ROP + $1 \mu \mathrm{g} / \mathrm{kg} \mathrm{DEX}$; Dex2, group administered $30 \mathrm{ml}$ 0.5\% ROP + $1.5 \mu \mathrm{g} / \mathrm{kg}$ DEX; Dex3, group administered $30 \mathrm{ml} 0.5 \% \mathrm{ROP}+2 \mu \mathrm{g} / \mathrm{kg}$ DEX; ROP, ropivacaine; DEX, dexmedetomidine.

each index at each time point between group Dex1 and Dex2 $(\mathrm{P}>0.05)$ (Fig. 2). There was no significant difference in $\mathrm{SpO}_{2}$ between the different time points in each group or among the different groups at each time point ( $>0.05$; Fig. 3$)$. 


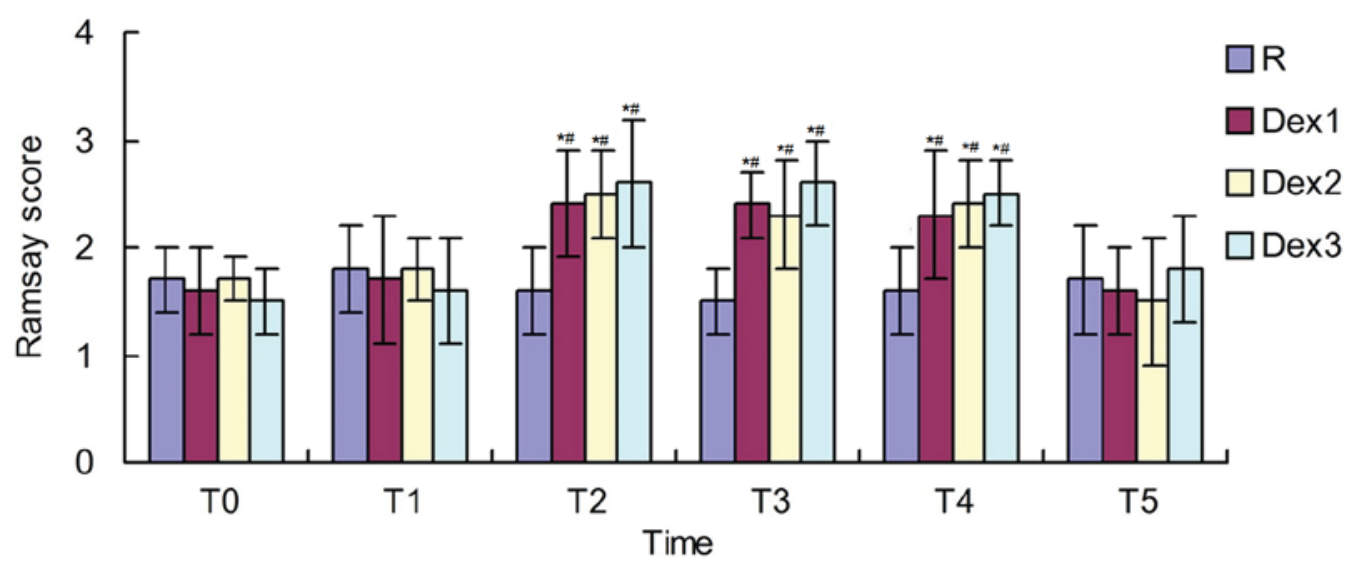

Figure 4. Comparison of Ramsay score among the four groups ( $\mathrm{n}=20$ /group). ${ }^{*} \mathrm{P}<0.01$ vs. the same group at T0 and $\mathrm{T} 1 ;{ }^{*} \mathrm{P}<0.01$ vs. group R at the same time point. R, group administered $30 \mathrm{ml}$ 5\% ROP; Dex1, group administered $30 \mathrm{ml} 0.5 \% \mathrm{ROP}+1 \mu \mathrm{g} / \mathrm{kg}$ DEX; Dex2, group administered $30 \mathrm{ml} 0.5 \%$ ROP + $1.5 \mu \mathrm{g} / \mathrm{kg}$ DEX; Dex3, group administered $30 \mathrm{ml}$ 0.5\% ROP + $2 \mu \mathrm{g} / \mathrm{kg}$ DEX; ROP, ropivacaine; DEX, dexmedetomidine.

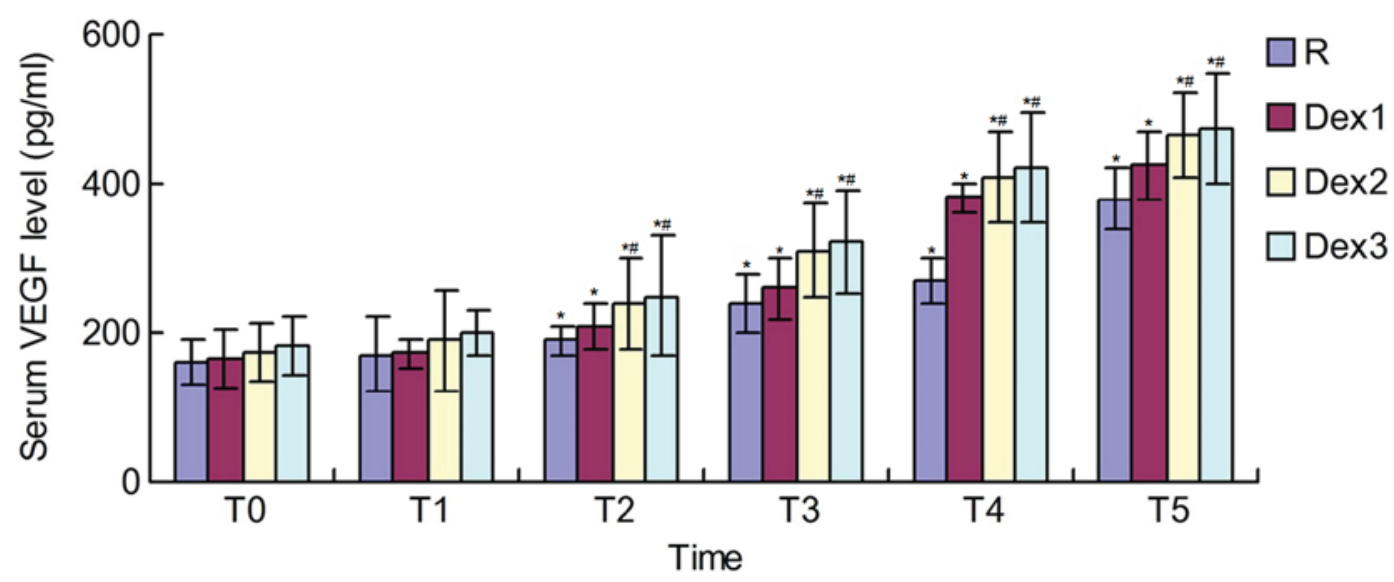

Figure 5. Comparison of serum VEGF level among the four groups ( $\mathrm{n}=20 /$ group). ${ }^{*} \mathrm{P}<0.01$ vs. the same group at $\mathrm{T} 0$ and $\mathrm{T} 1 ;{ }^{*} \mathrm{P}<0.01 \mathrm{vs}$. group $\mathrm{R}$ at the same time point. VEGF, vascular endothelial growth factor; R, group administered $30 \mathrm{ml} 5 \% \mathrm{ROP}$; Dex1, group administered $30 \mathrm{ml} 0.5 \% \mathrm{ROP}+1 \mu \mathrm{g} / \mathrm{kg} \mathrm{DEX}$; Dex2, group administered $30 \mathrm{ml}$ 0.5\% ROP $+1.5 \mu \mathrm{g} / \mathrm{kg}$ DEX; Dex3, group administered $30 \mathrm{ml} 0.5 \% \mathrm{ROP}+2 \mu \mathrm{g} / \mathrm{kg}$ DEX; ROP, ropivacaine; DEX, dexmedetomidine.

Comparison of Ramsay score among the four groups. The Ramsay score in groups Dex1-3 at T2-T4 were significantly higher than those in the same group at $\mathrm{T} 0$ and $\mathrm{T} 1$, respectively $(\mathrm{P}<0.01)$. There was no significant difference in the Ramsay score between the different time points in group $\mathrm{R}(\mathrm{P}>0.05)$. The Ramsay score in groups Dex1-3 at T2-T4 was significantly higher than that in group $\mathrm{R}(\mathrm{P}<0.05)$. There was no significant difference in each index at each time point among groups Dex1-3 (P>0.05) (Fig. 4).

Comparison of serum VEGF level among the four groups. The serum VEGF level in group R and Dex1-3 at T2-T5 was significantly higher than that of the same group at T0 and T1, respectively $(\mathrm{P}<0.01)$. The VEGF level in groups Dex 2 and Dex3 at T2-T5 was significantly higher than that in group R, respectively $(\mathrm{P}<0.01)$. There was no significant difference in each index at each time point between group Dex2 and Dex3 $(\mathrm{P}>0.05)$ (Fig. 5).

Comparison of adverse reactions during and following surgery among the four groups. There was no obvious adverse reaction during or following surgery in groups $\mathrm{R}$, Dex 1 or
Dex2, respectively. In group Dex3, there was $1(5 \%)$ case of over-sedation, 2 (10\%) cases of bradycardia and $1(5 \%)$ case of dry mouth during and following surgery, respectively (Table III).

\section{Discussion}

It has been demonstrated that the addition of drugs, including opioids, clonidine and DEX, to local anesthetics prolongs the duration of nerve block, thus delaying the appearance of patients' postoperative pain (19). In the United States and European countries, DEX has been applied outside the ranges regulated by the Food and Drug Administration's provisions and instructions, known as the 'off label' applications (20). The mechanism of DEX prolonging nerve block is currently not clear; therefore, further study is required. A study by Brummett et al (14) indicated in animal experiments that DEX combined with bupivacaine enhanced the duration of sensory and motor block of the sciatic nerve in mice. Furthermore, pathology has revealed that DEX has no long-term effects on postoperative axonal and myelin structure in the sciatic nerve of mice, and $\alpha 2 \mathrm{AR}$ antagonists cannot reverse its analgesic 
Table III. Comparison of adverse reactions during and following surgery among the four groups ( $\mathrm{n}=20 /$ group).

Group

\begin{tabular}{lcccc}
\cline { 2 - 5 } Adverse reaction & $\mathrm{R}$ & Dex1 & Dex2 & Dex3 \\
\hline Over-sedation & 0 & 0 & 0 & $1(5)^{\mathrm{a}}$ \\
Bradycardia & 0 & 0 & 0 & $2(10)^{\mathrm{a}}$ \\
Dry mouth & 0 & 0 & 0 & $1(5)^{\mathrm{a}}$ \\
Hypotension & 0 & 0 & 0 & 0 \\
Respiratory depression & 0 & 0 & 0 & 0 \\
Nerve root stimulation & 0 & 0 & 0 & 0 \\
Urine retention & 0 & 0 & 0 & 0 \\
Local anesthetic toxicity & 0 & 0 & 0 & 0 \\
\hline
\end{tabular}

${ }^{a}$ Data are presented as $\mathrm{n}$ ( $\%$ of cases). $\mathrm{R}$, group administered $30 \mathrm{ml}$ $5 \%$ ROP; Dex1, group administered $30 \mathrm{ml} 0.5 \% \mathrm{ROP}+1 \mu \mathrm{g} / \mathrm{kg}$ DEX; Dex2, group administered $30 \mathrm{ml} 0.5 \% \mathrm{ROP}+1.5 \mu \mathrm{g} / \mathrm{kg}$ DEX; Dex3, group administered $30 \mathrm{ml} 0.5 \% \mathrm{ROP}+2 \mu \mathrm{g} / \mathrm{kg}$ DEX; ROP, ropivacaine; DEX, dexmedetomidine.

effects (21). Therefore, the present experiment demonstrated that DEX is able to extend the nerve block time by acting on the peripheral nerve system. Another study revealed that DEX and ROP are effective in blocking nerve fiber conduction; however, ROP is more dominant and DEX serves simulative roles relative to ROP, which enhances the sensation and motor function of the blocked nerves (22). However, Kroin et al (23) demonstrated that the mechanism of $\alpha 2 \mathrm{AR}$ in extending the duration of local anesthetics with the participation of hyperpolarization-activated cation current.

Brummett et al (20) recommended the clinical dose of DEX in human peripheral nerve block as $2 \mu \mathrm{g} / \mathrm{kg}$. The present study investigated the impact of various doses of DEX on ROP-induced LSB. The results indicated that DEX combined with ROP significantly prolonged the duration of sensory and motor block compared with the use of ROP alone, and the effects were in the order of group Dex3>Dex2>Dex1. The onset time of nerve block among the four groups had no significant difference. Duma et al (24) demonstrated that $150 \mu \mathrm{g}$ clonidine combined with $40 \mathrm{mg}$ bupivacaine for brachial plexus block had no significant difference on the onset time of sensory and motor block; however, this combination significantly prolonged the block duration compared with that induced by the application of bupivacaine alone. This was consistent with the results of the present study. The present study also revealed that DEX had synergistic effects with local anesthetics, which prolonged the duration of sensory and motor block. Therefore, the present results suggest that DEX has the effects of a local anesthetic, consistent with the study of Marhofer et al study (15), which may be caused by the fact that $1.0 \mu \mathrm{g} / \mathrm{kg}$ DEX may have reached the maximum local anesthesia-like effect. With the increasing dose of DEX in the present study, the duration of sensory and motor block was gradually extended, and so the appearance of postoperative pain in patients was delayed and the anesthetic effects were improved. When the dose of DEX reached $2 \mu \mathrm{g} / \mathrm{kg}$, some patients exhibited over-sedation and circulatory suppression. Marhofer et al (15) further demonstrated that the duration of sensory block prolonged by DEX combined with ROP was six times that of the intravenous infusion of DEX, and it also indicates that DEX has good local anesthetic effects.

The results of the present study revealed that MAP and HR in groups Dex1-3 at T2-T5 were significantly lower than those in group $\mathrm{R}$. This may be derived from the anti-sympathetic effects of DEX, which may inhibit the sympathetic nerve terminal to release norepinephrine and enhance the activity of the vagus nerve, thus contributing to the intraoperative hemodynamic stability in patients (25). HR in group Dex3 at T3 and T4 was significantly lower than group Dex1 and Dex2, respectively. This indicated that the incidence of bradycardia at T3 and T4 in group Dex 3 is high, and it may be related to the inhibitory effect of DEX on sympathetic tension (25). This suggests that, in clinical applications, monitoring the cardiovascular system in patients must be strengthened so as to actively prevent and treat complications. The present study also demonstrated the strong sedative effects of DEX, while inducing no respiratory depression or other complications (26). The mechanism may be that DEX acts on $\alpha 2 \mathrm{AR}$ in the locus ceruleus of the brain stem, thus inhibiting neuronal discharging and resulting in natural non-REM sleep status (26).

In the present study, compared with group R, the Ramsay scores in groups Dex1-3 at T2-T4 were increased. VEGF is a special growth factor that acts on vascular endothelial cells (27). As the most important factor of angiogenesis, VEGF may promote the healing of injured joints (28). As the VEGF level in groups Dex2 and Dex3 at T2-T5 was significantly higher than that in group R, this indicates that DEX may promote the secretion of VEGF. However, different effects between the various DEX doses were not found.

In the present study, no obvious adverse reactions were observed during or following surgery in groups R, Dex 1 and Dex2. In group Dex3, there was $1(5 \%)$ case of over-sedation, $2(10 \%)$ cases of bradycardia and $1(5 \%)$ case of dry mouth during and following surgery. This indicates that a dose of DEX that is too high may lead to more adverse reactions.

In conclusion, $1,1.5$ and $2 \mu \mathrm{g} / \mathrm{kg}$ DEX extends the duration of $0.5 \%$ ROP-induced LSB, among which the latter two doses demonstrate a superior effect in prolonging the effect time of ROP. However, $2 \mu \mathrm{g} / \mathrm{kg}$ DEX exhibits a higher probability of inducing transient hypertension or bradycardia, which is not conducive to maintaining the stability of hemodynamics. Therefore, $1.5 \mu \mathrm{g} / \mathrm{kg}$ DEX may be recommended for obtaining the greatest effects for improving ROP-induced LSB. In the present study, the patients were limited to young and middle-aged populations; therefore, the appropriate doses of DEX for children and elderly patients require further investigation.

\section{Acknowledgements}

Not applicable.

\section{Funding}

No funding was received. 


\section{Availability of data and materials}

The datasets used and/or analyzed during the current study are available from the corresponding author on reasonable request.

\section{Authors' contributions}

JY and SS designed the study. SS and YN participated in data collection. JY and SS performed the experiments and statistical analysis. JY drafted the manuscript. All authors critically revised the manuscript. All authors read and approved the final manuscript.

\section{Ethics approval and consent to participate}

The present study was approved by the Medical Ethics Committee of the Central Hospital of Cangzhou. Written informed consent was obtained from all patients.

\section{Consent for publication}

Not applicable.

\section{Competing interests}

The authors declare that they have no competing interests.

\section{References}

1. Holzman RS: Unilateral Horner's syndrome and brachial plexus anesthesia during lumbar epidural blockade. J Clin Anesth 4: 464-466, 2002.

2. Marshall N and Watts S: Comparison of epidural anaesthesia with continuous lumbar plexus block for total hip arthroplasty. Region Anesth Pain Med 33: e155, 2008.

3. Wiis JT, Jensen-Gadegaard P, Altintas Ü, Seidelin C, Martusevicius R and Mantoni T: One-week postoperative patency of lower extremity in situ bypass graft comparing epidural and general anesthesia: Retrospective study of 822 patients. Ann Vasc Surg 28: 295-300, 2014

4. Karpel E, Marszolek P, Pawlak B and Wach E: Effectiveness and safety of unilateral spinal anaesthesia. Anestezjol Intens Ter 41: 33-36, 2009 (In Polish).

5. Hamilton TW, Athanassoglou V, Trivella M, Strickland LH, Mellon S, Murray D and Pandit HG: Liposomal bupivacaine peripheral nerve block for the management of postoperative pain. Cochrane Database Syst Rev 2016: CD011476, 2016.

6. Jeon YH: Easier and safer regional anesthesia and peripheral nerve block under ultrasound guidance. Korean J Pain 29: 1-2, 2016.

7. Salinas FV: Evidence basis for ultrasound guidance for lower-extremity peripheral nerve block: Update 2016. Reg Anesth Pain Med 41: 261-274, 2016.

8. Stewart J, Kellett N and Castro D: The central nervous system and cardiovascular effects of levobupivacaine and ropivacaine in healthy volunteers. Anesth Analg 97: 412-416, 2003.

9. Cherng $\mathrm{CH}$, Yang $\mathrm{CP}$ and Wong CS: Epidural fentanyl speeds the onset of sensory and motor blocks during epidural ropivacaine anesthesia. Anesth Analg 101: 1834-1837, 2005.

10. Kohane DS, Lu NT, Cairns BE and Berde CB: Effects of adrenergic agonists and antagonists on tetrodotoxin-induced nerve block. Reg Anesth Pain Med 26: 239-345, 2001.

11. Bhana N, Goa KL and Mcclellan KJ: Dexmedetomidine. Drugs 59: 263-270, 2000
12. Obayah GM, Refaie A, Aboushanab O, Ibraheem N and Abdelazees M: Addition of dexmedeto-midine to Bupivacaine for greater palatine nerve block prolongs post-operative analgesia after cleft palate repair. Eur J Anaesthesiol 27: 280-284, 2010.

13. Talke P, Xu M, Paloheimo M and Kalso E: Effects of intrathecally administered dexmedetomidine, MPV-2426 and tizanidine on EMG in rats. Acta Anaesthesiol Scand 47: 347-354, 2003.

14. Brummett CM, Padda AK, Amodeo FS, Welch KB and Lydic R: Pefineural dexmedeto-midine added to ropivacaine causes a dose-dependent increase in the duration of thermal antinociception in sciatic nerve block in rat. Anesthesiology 111: 1111-1119, 2009.

15. Marhofer D, Kettner SC, Marhofer P, Pils S, Weber M and Zeitlinger M: Dexmedetomidine as an adjuvant to ropivacaine prolongs peripheral nerve block: A volunteer study. Br J Anaesth 110: 438-442, 2013.

16. Kaya FN, Yavascaoglu B, Turker G, Yildirim A, Gurbet A, Mogol EB and Ozcan B: Intravenous dexmedetomidine, but not midazolam, prolongs bupivacaine spinal anesthesia. Can J Anasesth 57: 39-45, 2010

17. Fu KM, Smith JS, Polly DW Jr, Ames CP, Berven SH, Perra JH, McCarthy RE, Knapp DR Jr and Shaffrey CI; Scoliosis Research Society Morbidity and Mortality Committee: Correlation of higher preoperative American Society of Anesthesiology grade and increased morbidity and mortality rates in patients undergoing spine surgery. J Neurosurg Spine 14: 470-474, 2011.

18. Poon RT, Ng IO, Lau C, Zhu LX, Yu WC, Lo CM, Fan ST and Wong J: Serum vascular endothelial growth factor predicts venous invasion in hepatocellular carcinoma: A prospective study. Ann Surg 233: 227-235, 2001.

19. Crystal CS and Blankenship RB: Local anesthetics and peripheral nerve blocks in the emergency department. Emerg Med Clin North Am 23: 477-502, 2005.

20. Brummett CM, Norat MA,Palmisano JM and Lydic R: Perineural administration of dexmedetomidine in combination with bupivacaine enhances sensory and motor blockade in sciatic nerve block without inducing neurotoxicity in rat. Anesthesiology 109: 502-511, 2008.

21. Rangel RA, Marinho BG, Fernandes PD, de Moura RS and Lessa MA: Pharmacological mechanisms involved in the antinociceptive effects of dexmedetomidine in mice. Fundam Clin Pharmacol 28: 104-113, 2014.

22. Erlacher W, Schuschnig C, Koinig H, Marhofer P, Melischek M, Mayer N and Kapral S: Clonidine as adjuvant for meprivacaine, ropivacaine and bupivacaine in axillary, perivascular brachial plexus blaock. Can J Anaesth 48: 522-525, 2001.

23. Kroin JS, Buvonendran A, Beck DR, Topic JE, Watts DE and Tuman KJ: Clonidine prolongation of lidocaine analgesia after sciatic nerve block in rats is mediated via the hyperpolarization-activated cation current, not by alpha-adrenoreceptors. Anesthesiology 101: 488-494, 2004.

24. Duma A, Urbanek B, Sitzwohl C, Kreiger A, Zimpfer M and Kapral S: Clonidine as an adjuvant to local anaesthetic axillary brachial plexus block: A randomized, controlled study. Br J Anaesth 94: 112-116, 2005.

25. Penttilä J, Helminen A, Anttila M, Hinkka S and Scheinin H: Cardiovascular and parasympathetic effects of dexmedetomidine in healthy subjects. Can J Physiol Pharmacol 82: 359-362, 2004.

26. Jung HS, Joo JD, Jeon YS, Lee JA, Kim DW, In JH, Rhee HY and Choi JW: Comparison of an itraoperative infusion of dexmedetomidine or remifentanil on perioperative haemodynamics, hypnosis and sedation, and postoperative pain control. J Int Med Res 39: 1890-1899, 2011.

27. Gerber HP, Dixit V and Ferrara N: Vascular endothelial growth factor induces expression of the antiapoptotic proteins Bcl-2 and A1 in vascular endothelial cells. J Biol Chem 273: 13313-13316, 1998.

28. Becker R, Pufe T, Kulow S, Giessmann N, Neumann W, Mentlein R and Petersen W: Expression of vascular endothelial growth factor during healing of the meniscus in a rabbit model. J Bone Joint Surg Br 86: 1082-1087, 2004.

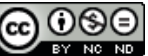

This work is licensed under a Creative Commons Attribution-NonCommercial-NoDerivatives 4.0 International (CC BY-NC-ND 4.0) License. 